\title{
C-Reactive Protein/Albumin Ratio as an Independent Predictor of Mortality in Critically III Pediatric Patients
}

\author{
Shereen A. Mohamed ${ }^{1}$ Rabab ElHawary ${ }^{1}$ \\ ${ }^{1}$ Department of Pediatrics, Kasr Alainy Faculty of Medicine, Cairo \\ University, Cairo, Egypt \\ J Child Sci 2020;10:e1-e11.
}

\begin{abstract}
Address for correspondence Shereen Abdelmonem Mohamed, Kasr Alainy Faculty of Medicine, Cairo University, Cairo 11562, Egypt (e-mail: shereen.mohamed@kasralainy.edu.eg).
\end{abstract}

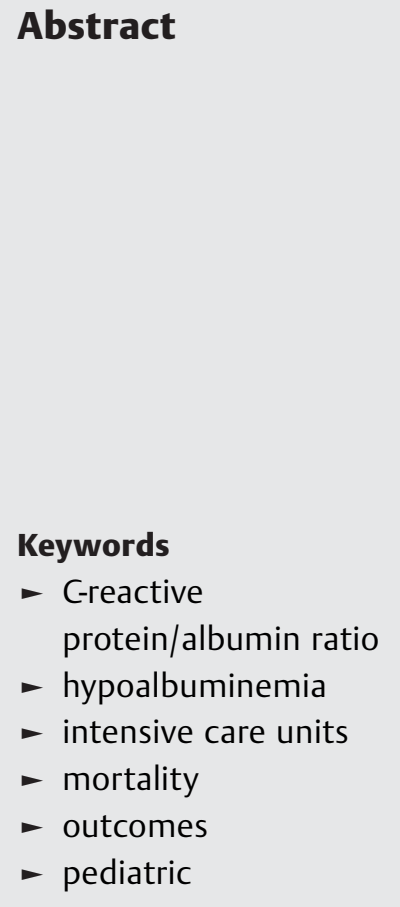

It is necessary to stratify the risk of pediatric patients at the time of intensive care unit (ICU) admission and to predict their outcomes. This helps to allocate the scarce ICU resources to start the appropriate treatment. The objective of this study was to evaluate the prognostic value of C-reactive protein/albumin ratio on admission to pediatric intensive care unit (PICU) in predicting mortality, PICU length of stay, the need for mechanical ventilation, and the use of inotropic drugs. This cohort study was conducted at Pediatric Cairo University Hospital. The study included 178 critically ill children. Pediatric Risk of Mortality-III (PRISM-III) score was calculated; CRP and serum albumin levels were assessed within 24 hours from admission. The median CRP/albumin ratio was significantly higher in nonsurvivors than survivors (18.60 and 4.65, respectively). The CRP/albumin ratio at a cutoff of $\geq 25.83$ had significant discriminatory power in predicting mortality (area under the curve [AUC] $=0.795$ and $p<0.001$ ) with $85.4 \%$ accuracy. Furthermore, CRP/albumin ratio alone showed a comparable discriminatory power to that of PRISM-III score (AUCs $=0.795$ and 0.793 , respectively). A multivariable logistic regression analysis revealed that each unit of increase in the CRP/albumin ratio increased the risk of mortality by 1.075 (odds ratio [OR] $=1.075$ ). CRP/albumin ratio showed a significantly higher median in ventilated (6.86) compared with non-ventilated (5.22) patients. Patients supported with inotropes showed significantly higher median CRP/albumin ratio (11.70 and 3.68, respectively). CRP/albumin ratio at admission to PICU was a good independent predictor of mortality.

\section{Introduction}

Critically ill children admitted to pediatric intensive care units (PICU) have a high risk of mortality. ${ }^{1}$ The present research is trying to optimize the consistency of care of these children to improve their short- and long-term outcomes. ${ }^{2}$

It seems necessary to stratify the risk of pediatric patients at the time of intensive care unit (ICU) admission and to predict their outcomes. ${ }^{3}$ This helps to allocate the scarce ICU resources, to start the appropriate treatment, and to satisfy the needs of the patients' families. ${ }^{4}$

Various prognostic scoring systems have been devised and validated in PICU. ${ }^{5}$ However, the applicability of many of these scales is precluded by the unavailability of resources.
Some scoring laboratory parameters are expensive, and their results may not be readily available on admission. ${ }^{6}$ Therefore, it is necessary to identify a simple, rapid, and readily accessible biomarker to confirm response to treatment and to predict prognosis of critically ill children at admission to the PICU.

C-reactive protein (CRP) is an acute phase protein that is produced following stimulation by various cytokines in response to infection, ischemia, trauma, and other inflammatory conditions. High CRP levels have been studied in relation to prognosis and mortality in critically ill patients. ${ }^{7}$ CRP has also been shown to be a poor predictor of mortality compared with other biomarkers in the pediatric population. ${ }^{8}$ received

October 23, 2019

accepted after revision

December 26, 2019
DOI https://doi.org/

10.1055/s-0040-1701623. ISSN 2474-5871.
Copyright (c) 2020 Georg Thieme Verlag License terms KG Stuttgart - New York 
Serum albumin is the main determining factor of colloid osmotic pressure and is a major plasma carrier of many hormones, drugs, and bioactive elements. ${ }^{9}$ Hypoalbuminemia at admission to a PICU has been investigated. It was associated with higher mortality and longer duration of mechanical ventilation. ${ }^{10}$

The prognostic performance of the CRP/albumin ratio has been investigated in critically ill adult patients and revealed favorable findings. ${ }^{7,11}$ However, it has not been evaluated in the pediatric population.

Based on this knowledge, the aim of our study was to evaluate the prognostic value of CRP/albumin ratio on admission to PICU in predicting mortality, the duration of PICU stay, and the need for mechanical ventilation, and inotrope use. Additionally, to compare the performance of CRP/albumin ratio with Pediatric Risk of Mortality-III (PRISM-III) score.

\section{Methods}

\section{Ethical Considerations}

The protocol of this study was approved by the Research Ethics Committee of the Faculty of Medicine, Cairo University. Informed consent was obtained from the patients' guardians. All patients' data were kept confidential after assigning a code number to each patient, known only by the researchers.

\section{Study Design and Setting}

This cohort study was conducted at Pediatric Cairo University Hospital, a tertiary educational medical institution. Data were collected from critically ill patients admitted to the PICU between March 2018 and February 2019.

\section{Eligibility Criteria}

Inclusion criteria: All patients admitted to the PICU of Pediatric Cairo University Hospital whose age was 1 month to less than 14 years were included.

Exclusion criteria: Patients aged less than 1 month or more than 14 years were excluded. Additionally, patients with severe protein-energy malnutrition; chronic liver disease/cirrhosis; nephrotic syndrome or nephritis; chronic gastrointestinal or kidney disease affecting the growth (malabsorption syndrome, celiac disease, inflammatory bowel disease, chronic renal failure); second or third-degree burns; and receipt of parenteral nutrition, blood products, or albumin before admission were also excluded.

\section{Collection of Data}

All patients were subjected to full history taking (including demographic data and reason for admission) and thorough medical assessment (including vital signs, nutritional status and systematic examination). All data were recorded in the data collection sheet. Patients were followed up until discharge or death, and the outcome measures (including mortality after PICU admission, the length of PICU stay, the need for mechanical ventilation, and the need for inotrope support) were recorded in the datasheet.

Pediatric Risk of Mortality-III score was calculated for each patient. This is an internationally validated score that assesses the risk of mortality. The score consists of age in addition to 17 physiological and laboratory parameters including systolic blood pressure, heart rate, temperature, pupillary response, mental status, acidosis, $\mathrm{pH}$, arterial partial pressure of carbon dioxide $\left(\mathrm{PaCO}_{2}\right)$, arterial partial pressure of oxygen $\left(\mathrm{PaO}_{2}\right)$, total carbon dioxide, prothrombin time (PT), partial thromboplastin time (PTT), blood glucose, serum concentrations of potassium, blood urea nitrogen (BUN), creatinine, and total white blood cells (WBCs) and platelet count. ${ }^{12}$

C-reactive protein and serum albumin levels were determined for all patients within the first 24 hours of admission. Albumin analysis was done using on automated auto analyzer (dimension clinical chemistry system). Hypoalbuminemia was defined as a serum albumin level of less than $3.5 \mathrm{~g} / \mathrm{dL}^{10}$ Serum concentration of CRP was determined by nephelometry on a Nephstar protein analyzer (Goldsite Diagnostic Inc., Shenzhen, China). CRP/albumin ratio was calculated using SPSS software program (Statistical Package for Social Science version 24 for windows; SPSS Inc., Chicago, IL, United States) by dividing serum CRP levels by serum albumin levels. Primary outcome was the survival to discharge. Secondary outcome was the Length of PICU stay, need for inotropes, and mechanical ventilation.

\section{Statistics}

Data analysis was performed using SPSS version 22. All numerical variables were checked for normality by Shapiro-Wilk test. Normally distributed numerical variables were presented as mean $\pm S D$, and differences between the two groups were tested using independent $t$-test. Abnormally distributed numerical variables were expressed as a median and interquartile range (25th-75th percentile), and differences between the two groups were tested using Mann-Whitney $U$ test. Categorical variables were summarized as frequencies and percentages, and the association between variables was tested using $x^{2}$ tests (Pearson's chi-square for independence or Fisher exact tests as appropriate). Spearman's rank correlation was performed between PICU stay and CRP/albumin ratio. The receiver operating characteristic (ROC) curve analyzed the discriminatory power of CRP/albumin ratio in predicting different outcomes. Cutoff values were identified along with associated sensitivity, specificity, and accuracy. A multivariable logistic regression analysis using forward stepwise (likelihood ratio) method was performed to determine the independent predictors of mortality. All variables showed significant differences between survivors and nonsurvivors (body mass index [BMI], serum CRP level, serum albumin level, CRP/albumin ratio,

PRISM III score, the need for mechanical ventilation, the need for inotropes, BUN, and platelets count) were included. A $p$-value of $\leq 0.05$ was considered statistically significant.

\section{Results}

Three hundred fifty critically ill patients were admitted to the PICU between March 2018 and February 2019. This study was undertaken on 178 critically ill children who fulfilled the eligibility criteria and all 178 patients were included. More than half (54.5\%) of them were males, and their ages ranged 
from 1.0 to 156.0 months with a median age of 11.0 $(\mathrm{IQR}=4.0-30.0)$

Thirty-six patients died with a mortality rate of $20.2 \%$. The mean BMI was significantly lower in nonsurvivors compared with survivors $(14.21 \pm 2.66$ and $15.49 \pm 3.36$, respectively, $p=0.035$ ). The median $\mathrm{CRP} /$ albumin ratio was significantly higher in nonsurvivors than survivors (18.60 and 4.65, respectively). Likewise, there were significant differences between survivors and nonsurvivors with regards to serum albumin and CRP levels. Additionally, the median PRISM-III score was significantly higher among nonsurvivors (7.0 and 2.0 , respectively). There was a statistically significant association between the need for mechanical ventilation and inotrope support and mortality $(p=0.001$ and $<0.001$, respectively). Higher percentages of nonsurvivors were mechanically ventilated and received inotropic drugs $(77.1 \%$ and $82.4 \%$, respectively). On the other hand, there were no significant differences between the two groups with regards

Table 1 Baseline characteristics of survivors and nonsurvivors

\begin{tabular}{|c|c|c|c|c|c|c|c|}
\hline & & & $\begin{array}{l}\text { Survivors } \\
N=142 \\
(79.8 \%)\end{array}$ & $\begin{array}{l}\text { Nonsurvivors } \\
\mathrm{N}=36 \\
(20.2 \%)\end{array}$ & Total $N=178$ & Test statistic & $p$-Value \\
\hline \multirow[t]{2}{*}{ Sex } & Female & $\mathrm{N}(\%)$ & $62(43.7 \%)$ & $19(52.8 \%)$ & $81(45.5 \%)$ & 0.962 & 0.327 \\
\hline & Male & $\mathrm{N}(\%)$ & $80(56.3 \%$ & 17 (47.2\%) & 97 (54.5\%) & & \\
\hline \multirow[t]{4}{*}{ Age (month) } & \multicolumn{2}{|l|}{ Range } & $1.0-156.0$ & $1.5-144.0$ & $1.0-156.0$ & 0.350 & 0.726 \\
\hline & \multicolumn{2}{|l|}{ Median } & 11.5 & 10.5 & 11.0 & & \\
\hline & \multicolumn{2}{|l|}{ IQR } & $4.0-30.0$ & $3.0-30.0$ & $4.0-30.0$ & & \\
\hline & \multicolumn{2}{|c|}{ Mean rank } & 90.18 & 86.82 & & & \\
\hline \multirow[t]{2}{*}{ BMI } & \multicolumn{2}{|l|}{ Range } & $8.62-28.84$ & $7.88-20.66$ & $7.88-28.84$ & 2.12 & $0.035^{a}$ \\
\hline & \multicolumn{2}{|c|}{ Mean \pm SD } & $15.49 \pm 3.36$ & $14.21 \pm 2.66$ & $15.23 \pm 3.27$ & & \\
\hline \multirow[t]{4}{*}{ Serum CRP } & \multicolumn{2}{|l|}{ Range } & $1.2-96.0$ & $9.9-150.0$ & 1.2 & 5.09 & $<0.001^{a}$ \\
\hline & \multicolumn{2}{|l|}{ Median } & 18.0 & 48.0 & 24.0 & & \\
\hline & \multicolumn{2}{|l|}{ IQR } & $12.0-48.0$ & $24.0-96.0$ & $12.0-48.0$ & & \\
\hline & \multicolumn{2}{|c|}{ Mean rank } & 79.68 & 128.25 & & & \\
\hline \multirow[t]{4}{*}{ Serum albumin } & \multicolumn{2}{|l|}{ Range } & $1.5-6.1$ & $1.7-5.3$ & $1.5-6.1$ & 3.79 & $<0.001^{a}$ \\
\hline & \multicolumn{2}{|l|}{ Median } & 3.7 & 3.1 & 3.7 & & \\
\hline & \multicolumn{2}{|l|}{ IQR } & $3.4-4.1$ & $2.6-3.7$ & $3.3-4.0$ & & \\
\hline & \multicolumn{2}{|c|}{ Mean rank } & 96.87 & 60.44 & & & \\
\hline \multirow[t]{5}{*}{ CRP/albumin } & \multicolumn{2}{|l|}{ Range } & $.30-30.97$ & $3.0-62.0$ & $.30-62.0$ & 5.45 & $<0.001^{a}$ \\
\hline & \multicolumn{2}{|l|}{ Median } & 4.65 & 18.60 & 6.23 & & \\
\hline & \multicolumn{2}{|l|}{ IQR } & $2.73-11.81$ & $6.67-32.0$ & $3.16-14.61$ & & \\
\hline & \multicolumn{2}{|c|}{ Mean rank } & 78.90 & 131.32 & & & \\
\hline & \multicolumn{2}{|l|}{ Range } & $0-19$ & $0-16$ & $0-19$ & 5.712 & $<0.001^{a}$ \\
\hline \multirow[t]{3}{*}{ PRISM-III score } & \multicolumn{2}{|l|}{ Median } & 2 & 7 & 3 & & \\
\hline & \multicolumn{2}{|l|}{ IQR } & $0-3$ & $3-10$ & $0-5$ & & \\
\hline & \multicolumn{2}{|c|}{ Mean rank } & 78.24 & 131.14 & & & \\
\hline \multirow[t]{3}{*}{ Serum creatinine } & \multicolumn{2}{|l|}{ Range } & $0.1-2.5$ & $0.1-4.2$ & $0.1-4.2$ & 1.95 & 0.055 \\
\hline & Median & & 0.5 & 0.6 & 0.5 & & \\
\hline & IQR & & $0.3-0.6$ & $0.3-0.9$ & $0.3-0.7$ & & \\
\hline
\end{tabular}

(Continued) to age, sex, serum creatinine, WBCs, or duration of stay in the PICU $(p>0.05)$ as shown in - Table 1.

- Table 2 shows a statistically significant association of the patient's diagnosis and mortality $(p<0.05)$. Significantly higher percentages of patients diagnosed as sepsis, CNS diseases, and CVS disorders were expired (30.6\%, 22.2\%, and $13.9 \%$, respectively).

Among the studied patients, 78 (43.8\%) needed mechanical ventilation. The CRP/albumin ratio showed a significantly higher median in ventilated (6.86) compared with nonventilated (5.22) patients. Also, the median albumin level was significantly lower in ventilated patients $(p=0.004)$. Otherwise, there was no significant differences between ventilated and nonventilated groups concerning their age, sex, serum CRP, or PRISM-III score $(p>0.05)$ as demonstrated in - Table 3.

In $68(38.2 \%)$ of the admitted children, inotropic drugs were administered. Patients supported with inotropes showed significantly higher median CRP/albumin ratio 
Table 1 (Continued)

\begin{tabular}{|c|c|c|c|c|c|c|}
\hline & & $\begin{array}{l}\text { Survivors } \\
N=142 \\
(79.8 \%)\end{array}$ & $\begin{array}{l}\text { Nonsurvivors } \\
\mathrm{N}=36 \\
(20.2 \%)\end{array}$ & Total $N=178$ & Test statistic & $p$-Value \\
\hline & Mean rank & 84.36 & 102.57 & & & \\
\hline \multirow[t]{4}{*}{ BUN } & Range & $0.3-78.6$ & $3.0-130.6$ & $0.3-130.6$ & 2.68 & $0.007^{\mathrm{a}}$ \\
\hline & Median & 17.0 & 30.5 & 20.0 & & \\
\hline & IQR & $12.0-30.0$ & $14.3-52.0$ & $12.0-33.4$ & & \\
\hline & Mean rank & 83.28 & 108.82 & & & \\
\hline \multirow[t]{4}{*}{ WBCs } & Range & $1.8-72.0$ & $.2-30.0$ & $0.2-72.0$ & 0.05 & 0.959 \\
\hline & Median & 11.5 & 11.8 & 11.6 & & \\
\hline & IQR & $8.3-16.9$ & $9.0-15.5$ & $8.3-16.7$ & & \\
\hline & Mean rank & 88.40 & 88.89 & & & \\
\hline \multirow[t]{4}{*}{ Platelets } & Range & $20.0-1007.0$ & $6.0-794.0$ & $6.0-1007.0$ & 3.75 & $<0.001^{\mathrm{a}}$ \\
\hline & Median & 331.5 & 203.5 & 310.0 & & \\
\hline & IQR & $216.0-436.0$ & $62.5-295.0$ & $184.0-423.0$ & & \\
\hline & Mean rank & 94.83 & 59.40 & & & \\
\hline \multirow[t]{4}{*}{ Duration of PICU stay (days) } & Range & $2-77$ & $1-55$ & $1-77$ & 0.122 & 0.903 \\
\hline & Median & 10 & 8 & 8 & & \\
\hline & $\mathrm{IQR}$ & $4-15$ & $5-15$ & $4-15$ & & \\
\hline & Mean rank & 81.76 & 82.85 & & & \\
\hline \multirow[t]{2}{*}{ Mechanical ventilation } & No & $62(54.9 \%)$ & $8(22.9 \%)$ & $70(47.3 \%)$ & 10.98 & $0.001^{\mathrm{a}}$ \\
\hline & Yes & $51(45.1 \%)$ & $27(77.1 \%)$ & 78 (52.7\%) & & \\
\hline \multirow[t]{2}{*}{ Inotrope use } & No & 74 (64.9\%) & $6(17.6 \%)$ & $80(54.1 \%)$ & 23.55 & $<0.001^{\mathrm{a}}$ \\
\hline & Yes & $40(35.1 \%)$ & $28(82.4 \%)$ & $68(45.9 \%)$ & & \\
\hline
\end{tabular}

Abbreviations: IQR, interquartile range; BMI, body mass index; SD, standard deviation; CRP, C-reactive protein; PRISM-III, Pediatric Risk of MortalityIII score; BUN, blood urea nitrogen; WBC, white blood cell; PICU, pediatric intensive care unit.

a'Significant at $p \leq 0.05$.

(11.70 and 3.68, respectively). In addition, the median CRP was significantly higher, while serum albumin was significantly lower in patients needed inotropes $(p<0.001$ and 0.003) (-Table 4).

Table 2 Association of the patient's diagnosis and mortality
Analysis of ROC curve for prediction of mortality using $\mathrm{CRP} /$ albumin ratio revealed that at a cutoff of $\geq 25.83$ had significant good discriminatory power in predicting mortality (AUC $=0.795$ and $p<0.001$ ) with $85.4 \%$ accuracy ( - Fig. 1 ).

\begin{tabular}{|c|c|c|c|c|c|c|c|c|c|}
\hline & & \multicolumn{6}{|c|}{ Mortality } & \multicolumn{2}{|c|}{ Fisher's exact test } \\
\hline & & \multicolumn{2}{|c|}{$\begin{array}{l}\text { Survivors } N \\
=142(79.8 \%)\end{array}$} & \multicolumn{2}{|c|}{$\begin{array}{l}\text { Nonsurvivors } \\
N=36(20.2 \%)\end{array}$} & \multicolumn{2}{|c|}{ Total $N=178$} & \multirow[b]{2}{*}{$x^{2}$} & \multirow[b]{2}{*}{$p$-Value } \\
\hline & & $\mathrm{N}$ & $\%$ & $\mathrm{~N}$ & $\%$ & $\mathrm{~N}$ & $\%$ & & \\
\hline \multirow[t]{8}{*}{ Diagnosis } & Respiratory & 53 & $37.6 \%$ & 7 & $19.4 \%$ & 60 & $33.9 \%$ & 13.012 & $0.049^{a}$ \\
\hline & CNS & 25 & $17.7 \%$ & 8 & $22.2 \%$ & 33 & $18.6 \%$ & & \\
\hline & Sepsis & 14 & $9.9 \%$ & 11 & $30.6 \%$ & 25 & $14.1 \%$ & & \\
\hline & Surgical & 20 & $14.2 \%$ & 3 & $8.3 \%$ & 23 & $13.0 \%$ & & \\
\hline & CVS & 14 & $9.9 \%$ & 5 & $13.9 \%$ & 19 & $10.7 \%$ & & \\
\hline & Metabolic & 7 & $5.0 \%$ & 1 & $2.8 \%$ & 8 & $4.5 \%$ & & \\
\hline & GIT & 5 & $3.5 \%$ & 0 & $0.0 \%$ & 5 & $2.8 \%$ & & \\
\hline & Others & 3 & $2.1 \%$ & 1 & $2.8 \%$ & 4 & $2.3 \%$ & & \\
\hline
\end{tabular}

Abbreviations: CNS, central nervous system; CVS, cardiovascular system; GIT, gastrointestinal tract.

${ }^{\mathrm{a}}$ Significant at $p \leq 0.05$. 
Table 3 Comparison of demographic data, serum CRP, serum albumin, CRP/albumin ratio, and PRISM-III score in relation to the need of mechanical ventilation

\begin{tabular}{|c|c|c|c|c|c|c|c|}
\hline & & & \multicolumn{3}{|c|}{ Mechanical ventilation } & \multirow[b]{2}{*}{ Test statistic } & \multirow[b]{2}{*}{$p$-Value } \\
\hline & & & $\begin{array}{l}\text { No } \\
N=70 \\
(39.3 \%)\end{array}$ & $\begin{array}{l}\text { Yes } \\
\mathrm{N}=78 \\
(43.8 \%)\end{array}$ & $\begin{array}{l}\text { Total } \\
\mathrm{N}=178\end{array}$ & & \\
\hline \multirow[t]{2}{*}{ Sex } & Female & $\mathrm{N}(\%)$ & $28(40.0 \%)$ & 40 (51.3\%) & 68 (45.9\%) & 1.89 & 0.169 \\
\hline & Male & $\mathrm{N}(\%)$ & $42(60.0 \%)$ & $38(48.7 \%)$ & $80(54.1 \%)$ & & \\
\hline \multirow[t]{4}{*}{ Age (month) } & \multicolumn{2}{|l|}{ Range } & $1.5-156.0$ & $1.0-156.0$ & $1.0-156.0$ & 1.797 & 0.072 \\
\hline & \multicolumn{2}{|l|}{ Median } & 12.5 & 7.0 & 10.5 & & \\
\hline & \multicolumn{2}{|l|}{ IQR } & $5.0-36.0$ & $3.0-30.0$ & $4.0-33.0$ & & \\
\hline & \multicolumn{2}{|c|}{ Mean rank } & 81.17 & 68.51 & & & \\
\hline \multirow[t]{4}{*}{ CRP/Albumin } & \multicolumn{2}{|l|}{ Range } & $0.33-30.96$ & $0.30-62.0$ & $0.30-62.0$ & 1.93 & $0.05^{\mathrm{a}}$ \\
\hline & \multicolumn{2}{|l|}{ Median } & 5.22 & 6.86 & 6.40 & & \\
\hline & \multicolumn{2}{|l|}{ IQR } & $1.22-14.62$ & $3.53-18.0$ & $3.12-15.52$ & & \\
\hline & \multicolumn{2}{|c|}{ Mean rank } & 67.30 & 80.96 & & & \\
\hline \multirow[t]{4}{*}{ Serum CRP } & \multicolumn{2}{|l|}{ Range } & $2.0-96.0$ & $1.2-150.0$ & $1.2-150.0$ & 1.96 & 0.091 \\
\hline & \multicolumn{2}{|l|}{ Median } & 21.0 & 24.0 & 24.0 & & \\
\hline & \multicolumn{2}{|l|}{ IQR } & $6.0-48.0$ & $12.0-48.0$ & $12.0-48.0$ & & \\
\hline & \multicolumn{2}{|c|}{ Mean rank } & 68.25 & 80.11 & & & \\
\hline \multirow[t]{4}{*}{ Serum albumin } & \multicolumn{2}{|l|}{ Range } & $1.5-6.1$ & $1.7-5.3$ & $1.5-6.1$ & 2.90 & $0.004^{\mathrm{a}}$ \\
\hline & \multicolumn{2}{|l|}{ Median } & 3.9 & 3.5 & 3.7 & & \\
\hline & \multicolumn{2}{|l|}{ IQR } & $3.5-4.3$ & $3.1-3.9$ & $3.3-4.1$ & & \\
\hline & \multicolumn{2}{|c|}{ Mean rank } & 85.29 & 64.81 & & & \\
\hline \multirow[t]{4}{*}{ PRISM-III score } & \multicolumn{2}{|l|}{ Range } & $0-19$ & $0-16$ & $0-19$ & 1.27 & 0.203 \\
\hline & \multicolumn{2}{|l|}{ Median } & 3 & 3 & 3 & & \\
\hline & \multicolumn{2}{|l|}{ IQR } & $0-6$ & $0-5$ & $0-6$ & & \\
\hline & \multicolumn{2}{|c|}{ Mean rank } & 78.75 & 69.84 & & & \\
\hline
\end{tabular}

Abbreviations: IQR, interquartile range; PRISM-III, Pediatric Risk of Mortality-III score.

aSignificant at $p \leq 0.05$.

Furthermore, CRP/albumin ratio showed a comparable discriminatory power to that of PRISM-III score (AUC $=0.793$ ), serum CRP $(A U C=0.773)$, and serum albumin $(A U C=0.705)$ with no significant difference $(p>0.05)$ as illustrated in -Table 5.

- Table 6 demonstrates that the CRP/albumin ratio at a cutoff $\geq 6.95$ had poor discriminatory power in predicting the need for mechanical ventilation ( $A U C=0.592, p=0.05$ ), with no significant difference from AUC (0.639) of serum albumin alone $(p=0.35)$ (-Table 6) (-Fig. 2). Whereas, $\mathrm{CRP} /$ albumin ratio at a cutoff $\geq 11.07$ showed significantly fair power in predicting the need for inotropic support (AUC $=0.742, \quad p<0.001$ ), with no significant difference from AUCs of serum CRP and albumin $(p>0.05)(-$ Table 7$)$ (-Fig. 3).

Concerning length of PICU stay, we found a significant positive poor correlation between the length of stay in ICU and CRP/albumin ratio $\left(r=0.28, p\right.$ value $\left.<0.0001^{*}\right)$. Additionally, we found nonsignificant differences between median CRP/albumin ratio of patients with short stay ( $\leq 3$ days) in comparison with patients who were stayed longer than 3 days as illustrated in - Table 8 .

A multivariable binomial logistic regression analysis was performed to determine independent predictors of mortality from variables that showed significant association with mortality. Among the studied variables, CRP/albumin ratio, PRISM-III score, the need of mechanical ventilation, and the need for inotropes were contributed significantly to the model. The logistic regression model was statistically significant $\left(X^{2}=64.38, p<0.001\right.$ ). The model explained $57.4 \%$ (Nagelkerke $\mathrm{R}^{2}$ ) of the variance and correctly classified 90.7\% of cases. Each unit of increase in CRP/albumin ratio increased the risk of mortality by 1.079 (adjusted $\mathrm{OR}=1.079$ ).

Each unit of increase in PRISM-III was associated with a significant increase of the risk of mortality by more than onefold (adjusted $\mathrm{OR}=1.27$ ). Moreover, mechanical ventilation and the need for inotropes increased the likelihood of mortality by $20.4 \%$ and $25.5 .0 \%$ (adjusted $\mathrm{OR}=0.204$ and 0.255 , respectively) (-Table 9 ). 
Table 4 Comparison of demographic data, serum CRP, serum albumin, CRP/albumin ratio, and PRISM-III score and inotrope use

\begin{tabular}{|c|c|c|c|c|c|c|c|}
\hline & & & \multicolumn{3}{|l|}{ Inotrope use } & \multirow[b]{2}{*}{ Test statistic } & \multirow[b]{2}{*}{ p-Value } \\
\hline & & & $\begin{array}{l}\text { No } \\
N=80 \\
(44.9 \%)\end{array}$ & $\begin{array}{l}\text { Yes } \\
N=68 \\
(38.2 \%)\end{array}$ & Total $N=178$ & & \\
\hline \multirow[t]{2}{*}{ Sex } & Female & $\mathrm{N}(\%)$ & $34(42.5 \%)$ & 35 (51.5\%) & $69(46.6 \%)$ & 1.189 & 0.276 \\
\hline & Male & $\mathrm{N}(\%)$ & $46(57.5 \%)$ & $33(48.5 \%)$ & 79 (53.4\%) & & \\
\hline \multirow[t]{3}{*}{ Age (month) } & \multicolumn{2}{|l|}{ Range } & $1.0-156.0$ & $1.5-156.0$ & $1.0-156.0$ & 1.27 & 0.202 \\
\hline & \multicolumn{2}{|c|}{ Median (IQR) } & $11.5(4.0-36.0)$ & $7.5(3.0-19.0)$ & $8.0(3.9-24.0)$ & & \\
\hline & \multicolumn{2}{|c|}{ Mean rank } & 78.63 & 69.94 & & & \\
\hline \multirow[t]{3}{*}{ CRP/albumin } & \multicolumn{2}{|l|}{ Range } & $0.30-30.97$ & $0.49-62.0$ & $0.30-62.0$ & 5.70 & $<0.001^{\mathrm{a}}$ \\
\hline & \multicolumn{2}{|c|}{ Median (IQR) } & $3.68(0.67-8.76)$ & $11.70(4.07-23.37)$ & $6.15(0.30-14.87)$ & & \\
\hline & \multicolumn{2}{|c|}{ Mean rank } & 58.03 & 93.88 & & & \\
\hline \multirow[t]{4}{*}{ Serum CRP } & \multicolumn{2}{|l|}{ Range } & $1.2-96.0$ & $2.0-150.0$ & $1.2-150.0$ & 4.91 & $<0.001^{\mathrm{a}}$ \\
\hline & \multicolumn{2}{|l|}{ Median } & 12.0 & 47.0 & 24.0 & & \\
\hline & \multicolumn{2}{|l|}{ IQR } & $2.0-33.8$ & $12.0-80.0$ & $12.0-48.0$ & & \\
\hline & \multicolumn{2}{|c|}{ Mean rank } & 58.58 & 93.24 & & & \\
\hline \multirow[t]{4}{*}{ Serum albumin } & \multicolumn{2}{|l|}{ Range } & $1.5-6.1$ & $1.7-5.5$ & $1.5-6.1$ & 3.41 & $0.001^{\mathrm{a}}$ \\
\hline & \multicolumn{2}{|l|}{ Median } & 3.8 & 3.4 & 3.7 & & \\
\hline & \multicolumn{2}{|l|}{ IQR } & $3.5-4.2$ & $3.0-3.9$ & $3.3-4.1$ & & \\
\hline & \multicolumn{2}{|c|}{ Mean rank } & 85.59 & 61.46 & & & \\
\hline \multirow[t]{3}{*}{ PRISM-III score } & \multicolumn{2}{|l|}{ Range } & $0-19$ & $0-16$ & $0-19$ & 0.178 & 0.858 \\
\hline & \multicolumn{2}{|c|}{ Median (IQR) } & $3(0-5)$ & $3(0-7)$ & $3(0-5)$ & & \\
\hline & \multicolumn{2}{|c|}{ Mean rank } & 74.56 & 73.35 & & & \\
\hline
\end{tabular}

Abbreviations: CRP, C-reactive protein; PRISM-III, PRISM-III, Pediatric Risk of Mortality-III score; IQR, interquartile range.

${ }^{\text {a }}$ Significant at $p \leq 0.05$.

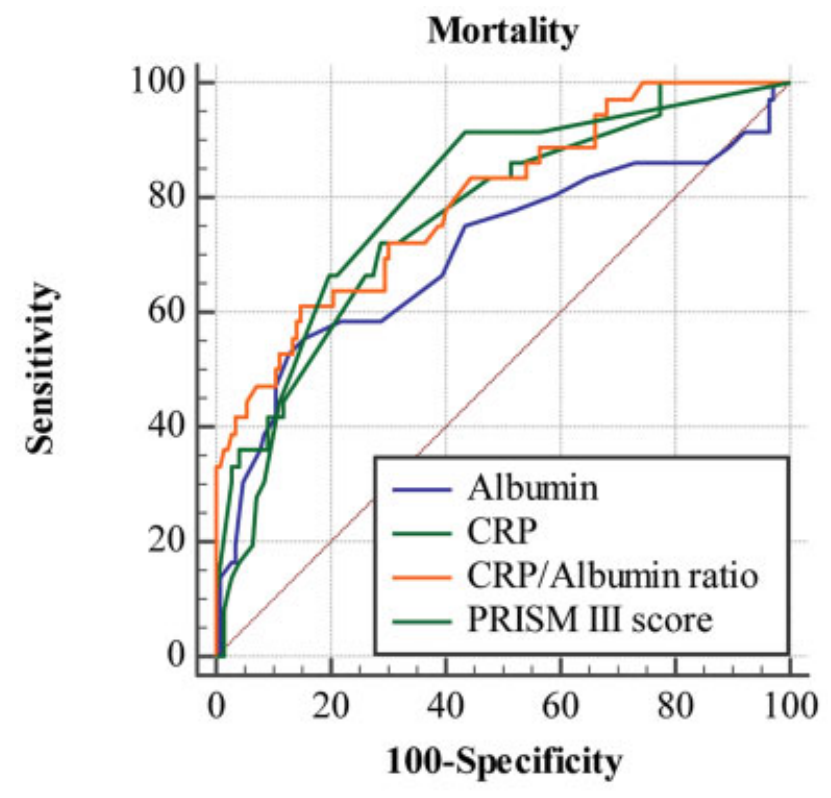

Fig. 1 Receiver operating curves of C-reactive protein (CRP)/albumin ratio, serum albumin, serum CRP, and Pediatric Risk of Mortality-III (PRISM-III) score in predicting mortality.
- Table 10 shows that 16 (11.2\%) patients had CRP/ albumin ratio $\geq 25.83$. There was significant association between high cutoff and the need for inotropes and mortality $(p<0.001)$.

\section{Discussion}

The C-reactive protein/albumin ratio has recently emerged as a prognostic marker of mortality in critically ill adult patients. ${ }^{7}$ To the best of our knowledge, this was the first study to assess the prognostic value of $\mathrm{CRP} /$ albumin ratio in critically ill children admitted to PICU.

In the present study, the CRP/albumin ratio determined within the first 24 hours of admission was significantly higher in non-survivors than survivors. ROC curve analysis with CRP/albumin ratio at a cutoff of $\geq 25.83$ was significantly predictive of mortality with $85.4 \%$ accuracy. Moreover, CRP/albumin ratio showed a comparable discriminatory power to that of serum CRP, serum albumin, and PRISM-III score. Multivariable regression analysis revealed that CRP/albumin ratio, PRISM-III score, and the need for mechanical ventilation and inotropes were significant independent predictors of mortality. CRP/albumin ratio also showed poor to fair predictive power of the need for mechanical ventilation and inotropic support. 
Table 5 The best cutoff values, sensitivity, specificity, and AUC of PRISM III score and CRP/albumin ratio, serum CRP, and serum albumin in predicting mortality

\begin{tabular}{|l|l|l|l|l|l|l|l|}
\hline Mortality & Cutoff & Sensitivity (\%) & Specificity (\%) & AUC & $95 \%$ CI & Accuracy\% & $p$-Value \\
\hline PRISM III score & $\geq 10.5$ & 19.4 & 94.3 & 0.793 & $0.726-0.850$ & 79.1 & $<0.001^{\mathrm{a}}$ \\
\hline CRP/albumin ratio & $\geq 25.83$ & 41.7 & 96.5 & 0.795 & $0.727-0.851$ & 85.4 & $<0.001^{\mathrm{a}}$ \\
\hline Serum CRP & $>38$ & 72.22 & 71.13 & 0.773 & 0.704 To 0.832 & 83.1 & $<0.001^{\mathrm{a}}$ \\
\hline Serum albumin & $\leq 3.1$ & 52.78 & 87.32 & 0.705 & 0.632 to 0.771 & 82.0 & $0.003^{*}$ \\
\hline
\end{tabular}

Abbreviations: AUC, area under the curve; CRP, C-reactive protein; PRISM-III, PRISM-III, Pediatric Risk of Mortality-III score.

Note: Pairwise comparison of ROC curves (based on difference between areas under the curve) revealed nonsignificant difference between them $(p>0.05)$.

a Significant at $p \leq 0.05$.

Table 6 The best cutoff values, sensitivity, specificity, and AUC of CRP/albumin ratio, and serum albumin in predicting the need of mechanical ventilation

\begin{tabular}{|l|l|l|l|l|l|l|l|}
\hline MV & Cutoff & Sensitivity (\%) & Specificity (\%) & AUC & $95 \%$ CI & Accuracy \% & $p$-Value \\
\hline CRP/albumin ratio & $\geq 6.95$ & 48.7 & 58.6 & 0.592 & $0.509-0.672$ & 53.4 & $0.050^{\text {a }}$ \\
\hline Serum albumin & $\leq 3.8$ & 73.08 & 51.43 & 0.638 & 0.555 to 0.716 & 62.8 & $0.003^{\text {a }}$ \\
\hline
\end{tabular}

Abbreviations: AUC, area under the curve; CRP, C-reactive protein; MV, mechanical ventilation.

Note: Pairwise comparison of ROC curves (based on difference between areas under the curve) revealed nonsignificant difference between them $(p=0.35)$.

asignificant at $p \leq 0.05$.

C-reactive protein is a serum acute phase reactant and a valuable inflammatory biomarker in various clinical conditions. C-reactive protein levels can be easily measured, and its assays are inexpensive and convenient. Additionally, CRP is a stable protein that provides similar results in fresh or stored state. Moreover, it does not vary from person to person or influenced by genetic makeup or gender of the patient. ${ }^{13}$

$\mathrm{C}$-reactive protein has been used as a prognostic marker in critical care settings. ${ }^{13}$ It has been reported that CRP level

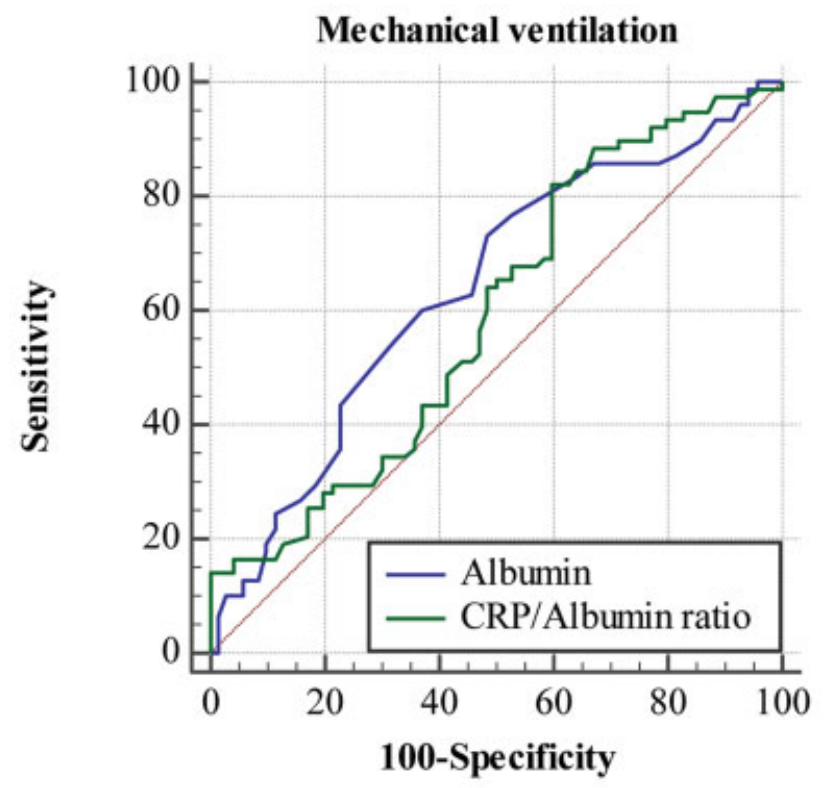

Fig. 2 Receiver operating curves of C-reactive protein (CRP)/albumin ratio and albumin in predicting the need of mechanical ventilation. was associated with an increased risk of mortality in chronic obstructive pulmonary disease. ${ }^{14}$ In pediatric noncardiovascular critically ill patients CRP was found to be an independent predictor of PICU mortality. ${ }^{15}$ On the other hand, CRP has been shown to have a poor prognostic value of mortality compared with other biomarkers in the pediatric population. ${ }^{8}$ Elevated CRP levels at ICU discharge represented only a very moderate risk factor for readmission and in-hospital mortality and they might not be enough for individual clinical decision-making. ${ }^{16}$

Hypoalbuminemia has been advocated as a simple, cheap, and consistent indicator of outcome in critically ill adults and children admitted to ICU in different pathologic conditions. ${ }^{17}$

In a prospective observational study conducted at the PICU of a tertiary care hospital, hypoalbuminemia has been found to be a significant predictor of mortality and morbidity in critically ill children. ${ }^{18}$ In addition, the outcome of critically ill children with hypoalbuminemia admitted to a tertiary care center was assessed. A very important role of albumin levels in determining the treatment options and the outcome of the treatment was detected. Besides, albumin levels were associated with the rate of morbidity and mortality. ${ }^{19}$ Subsidiary evidence was reported by Moustafa et al, ${ }^{20}$ where hypoalbuminemia was a frequent feature in critically Ill children admitted to PICU in Alexandria University Children's Hospital. Albumin levels obtained at admission demonstrated statistically significant associations with clinical outcomes including longer length of PICU stay and higher mortality. ${ }^{20}$

As a potential outcome predictor, serum albumin level has been added as a component parameter in the Acute Physiology And Chronic Health Evaluation (APACHE)-III score. ${ }^{21}$ However, hypoalbuminemia can be caused by previous 
Table 7 The best cutoff values, sensitivity, specificity, and AUC of CRP/albumin ratio, serum CRP, and serum albumin in predicting inotrope use

\begin{tabular}{|l|l|l|l|l|l|l|l|}
\hline Inotrope use & Cutoff & Sensitivity (\%) & Specificity (\%) & AUC & 95\% CI & Accuracy \% & $p$-Value \\
\hline CRP/albumin ratio & $\geq 11.07$ & 50 & 77.5 & 0.742 & $0.664-0.810$ & 64.9 & $<0.001^{\text {a }}$ \\
\hline Serum CRP & $>38$ & 55.88 & 77.50 & 0.734 & $0.655-0.803$ & 67.6 & $<0.0001$ \\
\hline Serum albumin & $\leq 3.4$ & 52.94 & 81.25 & 0.663 & $0.581-0.739$ & 64.9 & $0.0005^{\text {a }}$ \\
\hline
\end{tabular}

Abbreviations: AUC, area under the curve; CRP, C-reactive protein; $\mathrm{Cl}$, confidence interval.

Note: Pairwise comparison of ROC curves (based on difference between areas under the curve) revealed nonsignificant difference between them $(p>0.05)$.

${ }^{\mathrm{a}}$ Significant at $p \leq 0.05$.

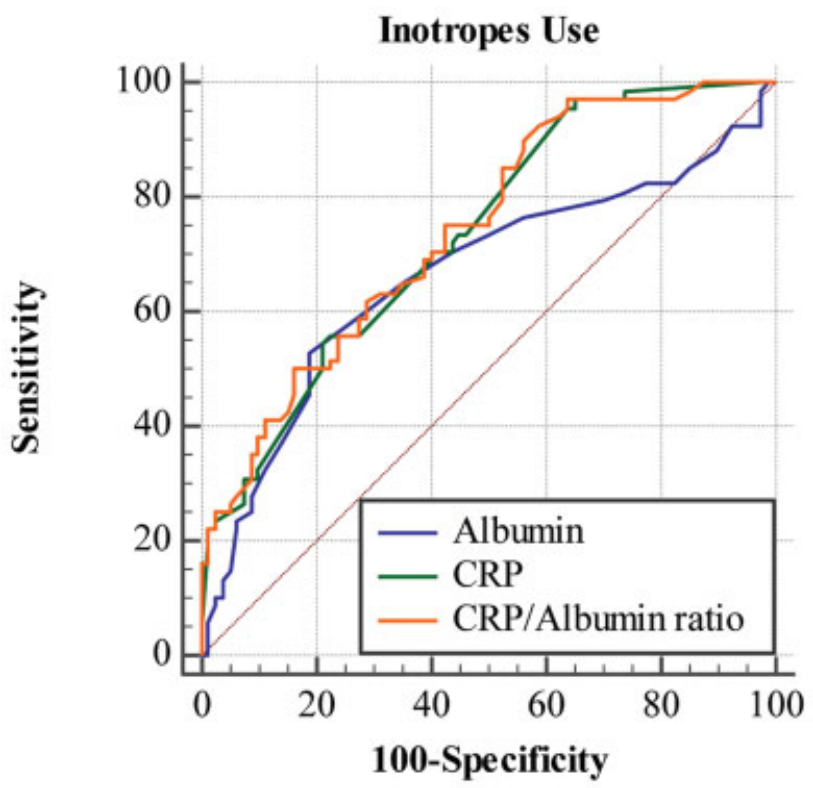

Fig. 3 Receiver operating curves of C-reactive protein (CRP)/albumin ratio, serum albumin, and serum CRP in predicting the need of inotrope support.

illness or general conditions, such as liver disease, kidney damage, and malnutrition. ${ }^{22}$ To avoid these weaknesses, a combination of CRP and albumin may be more valuable prognostic markers for outcomes across various diseases, providing both inflammatory and nutritional information. ${ }^{11}$ Since the combination of albumin and CRP into a single index has been suggested, subsequent studies have shown that the $\mathrm{CRP} /$ albumin ratio is more reliable for prognosis than CRP or albumin alone. ${ }^{23}$
In the current study, the CRP/albumin ratio determined within the first 24 hours of admission was significantly higher in non-survivors than survivors. Comparable findings were reported by Park et al, ${ }^{7}$ who reported a greater accuracy of CRP/albumin ratio compared with CRP alone for predicting mortality. Furthermore, the CRP/albumin ratio was an independent risk factor for mortality at 28 days in critically ill adult patients admitted to the ICU. Further study in older adults concluded that the CRP/albumin ratio at admission to the ED was associated with all-cause in-hospital mortality. ${ }^{11}$ As well, CRP/albumin ratio was an independent predictor of 180-day mortality in adults with severe sepsis or septic shock. ${ }^{24}$ Moreover, CRP/albumin ratio was useful prognostic tool for overall survival in adult surgical oncology patients. ${ }^{25,26} \mathrm{CRP} /$ albumin ratio was also found to be a potentially useful prognostic marker for predicting a poor prognosis in ST elevation myocardial infarction patients. ${ }^{27}$

Based on the ROC curve results, cutoff values of $\geq 25.83$ for the CRP/albumin ratio were found to be significantly predictive of mortality with $85.4 \%$ accuracy. Comparison of CRP/albumin ratio discriminatory power with that of PRISM-III, which is a validated scoring system for assessing the risk of mortality among children was assessed. The present study revealed that $\mathrm{CRP} /$ albumin ratio alone showed a comparable discriminatory power to that of PRISM-III score. This is a valuable finding because the CRP/albumin ratio is relatively simple and easy to use in all settings when compared with the extensive variables of PRISM-III score. ${ }^{7}$

Mortality is the most frequently assessed outcome, but the morbidity outcomes as the need for mechanical ventilation and inotropic drugs, besides the length of stay in PICU are also important. ${ }^{17}$

Table 8 Correlation between the length of PICU stay and CRP/albumin ratio

\begin{tabular}{|l|l|l|l|l|l|}
\hline & \multicolumn{3}{|l|}{ Duration of PICU stay } & \multicolumn{2}{l|}{ Mann-Whitney $U$ test } \\
\hline & & $\leq 3$ days & $>3$ days & Z mw & $p$-Value \\
\hline CRP/albumin ratio & Range & $0.30-56.47$ & $0.36-62.0$ & 1.86 & 0.062 \\
\hline & Median & 3.43 & 6.49 & & \\
\hline & IQR & $0.85-12.97$ & $3.43-15.36$ & & \\
\hline & Mean rank & 67.16 & 85.21 & & \\
\hline
\end{tabular}

Abbreviations: PICU, pediatric intensive care unit; CRP, C-reactive protein; IQR, interquartile range. 
Table 9 Multivariable binary logistic regression for determining independent predictors of mortality

\begin{tabular}{|c|c|c|c|c|c|c|}
\hline \multicolumn{2}{|c|}{ Chi-square test } & \multirow[t]{2}{*}{ Nagelkerke $R^{2}$} & \multirow{2}{*}{$\begin{array}{l}\text { Percentage accuracy } \\
\text { in classification }\end{array}$} & \multirow[t]{2}{*}{ Variables } & \multirow[t]{2}{*}{ Adjusted odds ratio } & \multirow[t]{2}{*}{$p$-Value } \\
\hline$x^{2}$ & $p$-Value & & & & & \\
\hline \multirow[t]{5}{*}{64.38} & $<0.001^{\mathrm{a}}$ & $57.4 \%$ & $90.7 \%$ & Mechanical ventilation & 0.204 & $0.020^{\mathrm{a}}$ \\
\hline & & & & Inotropes use & 0.255 & $0.045^{\mathrm{a}}$ \\
\hline & & & & CRP/albumin ratio & 1.079 & $0.008^{\mathrm{a}}$ \\
\hline & & & & PRISM III score & 1.27 & $<0.001^{\mathrm{a}}$ \\
\hline & & & & Constant & 0.161 & $0.002^{\mathrm{a}}$ \\
\hline
\end{tabular}

Abbreviations: CRP, C-reactive protein; PRISM-III, PRISM-III, Pediatric Risk of Mortality-III score.

${ }^{a}$ Significant at $p \leq 0.05$.

In this study, CRP/albumin ratio showed a significantly higher median in ventilated (6.86) compared with nonventilated (5.22) patients. However, the CRP/albumin ratio at a cutoff $\geq 6.95$ showed a poor discriminatory power in predicting the need for mechanical ventilation $(A U C=0.592)$. Parallel to this finding, it has been stated that hypoalbuminemia at admission to a PICU was associated with a higher likelihood of the need for, ${ }^{20}$ as well as the duration of mechanical ventilation. ${ }^{10}$

In the present study, patients supported with inotropes showed significantly higher median CRP/albumin ratio
(11.70 and 3.68, respectively). ROC curve results demonstrated that CRP/albumin ratio at a cutoff $\geq 11.07$ had significantly moderate power in predicting the need for inotropic support.

The current study revealed poor association between CRP/albumin ratio and PICU stay. Compared with our finding in pediatric patients, Li et $\mathrm{al}^{28}$ have demonstrated significantly increased total length of hospital stay in adult patients admitted to medical ICU with CRP/prealbumin more than 0.24 . Another study has reported a significantly

Table 10 Comparison of patient's groups based on CRP/albumin ratio cutoff

\begin{tabular}{|c|c|c|c|c|c|c|}
\hline & & & \multicolumn{2}{|l|}{ CRP/albumin ratio } & \multicolumn{2}{|c|}{ Tests of significance } \\
\hline & & & $\begin{array}{l}<25.83 \\
N=160(88.8 \%)\end{array}$ & $\begin{array}{l}\geq 25.83 \\
N=20 \\
(11.2 \%)\end{array}$ & Test statistic & p-Value \\
\hline \multirow[t]{4}{*}{ Sex } & Female & $\mathrm{N}$ & 71 & 10 & 2.047 & 0.152 \\
\hline & & $\%$ & $43.8 \%$ & $62.5 \%$ & & \\
\hline & Male & $\mathrm{N}$ & 91 & 6 & & \\
\hline & & $\%$ & $56.2 \%$ & $37.5 \%$ & & \\
\hline \multirow[t]{2}{*}{ Age (month) } & \multicolumn{2}{|c|}{ Median } & 10.5 & 15.0 & 0.120 & 0.905 \\
\hline & \multicolumn{2}{|l|}{ IQR } & $4.0-30.0$ & $4.0-22.0$ & & \\
\hline BMI & \multicolumn{2}{|c|}{ Mean \pm SD } & $15.28 \pm 3.39$ & $14.74 \pm 1.58$ & 1.135 & 0.265 \\
\hline \multirow[t]{4}{*}{ Mechanical ventilation } & No & $\mathrm{N}$ & 66 & 4 & 2.175 & 0.140 \\
\hline & & $\%$ & $49.3 \%$ & $28.6 \%$ & & \\
\hline & Yes & $\mathrm{N}$ & 68 & 10 & & \\
\hline & & $\%$ & $50.7 \%$ & $71.4 \%$ & & \\
\hline \multirow[t]{4}{*}{ Inotropes use } & No & $\mathrm{N}$ & 79 & 1 & 15.09 & $<0.001^{a}$ \\
\hline & & $\%$ & $59.4 \%$ & $6.7 \%$ & & \\
\hline & Yes & $\mathrm{N}$ & 54 & 14 & & \\
\hline & & $\%$ & $40.6 \%$ & $93.3 \%$ & & \\
\hline \multirow[t]{4}{*}{ Mortality } & No & N & 137 & 5 & 38.162 & $<0.001^{\mathrm{a}}$ \\
\hline & & $\%$ & $86.7 \%$ & $25.0 \%$ & & \\
\hline & Yes & $\mathrm{N}$ & 21 & 15 & & \\
\hline & & $\%$ & $13.3 \%$ & $75.0 \%$ & & \\
\hline
\end{tabular}

Abbreviations: CRP, C-reactive protein, BMI, body mass index, SD, standard deviation.

${ }^{\text {a }}$ Significant at $p \leq 0.05$. 
higher CRP/prealbumin in ICU adult patients with severe pancreatitis who had a longer period of ICU stay. ${ }^{29}$

For accurate estimation of the magnitude of risk of $\mathrm{CRP} /$ albumin ratio on mortality and for determining other risk factors of mortality a multivariable analysis binomial logistic regression analysis was applied. It revealed that CRP/albumin ratio, PRISM-III score, and the need for mechanical ventilation and inotropes were significant independent predictors of mortality. Each unit of increase in $\mathrm{CRP} /$ albumin ratio increased the risk of mortality by 1.075 (adjusted $\mathrm{OR}=1.075$ ). Each unit of increase in PRISM-III was associated with a significant increase of the risk of mortality by more than one-fold (adjusted $\mathrm{OR}=1.285$ ). Moreover, mechanical ventilation and inotropic support increased the likelihood of mortality by $20.3 \%$ and $24.0 \%$ (adjusted $\mathrm{OR}=0.203$ and 0.240 , respectively).

Integration of CRP/albumin ratio with PRISM-III score showed higher accuracy (90.9\%) in predicting mortality than either predictor alone (85.4\% and $79.1 \%$, respectively). Similarly, the addition of serum albumin to other scoring systems as APACHE-III and IV scores was beneficial. ${ }^{30}$ However, the CRP/albumin ratio alone may provide some advantages in time and cost.

\section{Conclusion}

CRP/albumin ratio within 24 hours of admission to a PICU was a good independent predictor of mortality. CRP/albumin ratio alone showed a comparable predictive power of PRISMIII score. So, the use of the CRP/albumin ratio alone helps to identify patients at greater risk of mortality to make prompt therapeutic decisions. Integration of CRP/albumin ratio with PRISM-III score showed higher accuracy in predicting mortality than either predictor alone. Furthermore, CRP/albumin ratio was a poor predictor of the need for mechanical ventilation, and a moderate predictor of the need for inotropic drugs.

Small-sized cohort was the limitation of this study, so we recommend further multicenter studies including higher numbers of patients.

\section{Authors' Contributions}

S.A.M. did the study design, collected the data, and wrote the manuscript. R.H. did the laboratory work and shared in the study design. All authors have revised and approved the manuscript.

\section{Note}

The datasets used and/or analyzed during the current study are available from the corresponding author on reasonable request.

\section{Funding \\ None.}

\section{Conflict of Interest}

None declared.

\section{References}

1 Lim K, Ruangnapa K, Sucheewakul S, Anantaseree W, Liabsuetrakul T, McNeil E. Validation of a modified pediatric risk of mortality III model in a pediatric intensive care unit in Thailand. Pediatric Respirology and Critical Care Medicine 2018;2(04):65

2 Quasney MW, López-Fernández YM, Santschi M, Watson RS; Pediatric Acute Lung Injury Consensus Conference Group. The outcomes of children with pediatric acute respiratory distress syndrome: proceedings from the Pediatric Acute Lung Injury Consensus Conference. Pediatr Crit Care Med 2015;16(05, Suppl 1):S118-S131

3 Packham V, Hampshire P. Critical care admission for acute medical patients. Clin Med (Lond) 2015;15(04):388-391

4 James FR, Power N, Laha S. Decision-making in intensive care medicine - A review. J Intensive Care Soc 2018;19(03): 247-258

$5 \mathrm{Hu}$ L, Zhu Y, Chen M, et al. Development and validation of a disease severity scoring model for pediatric sepsis. Iran J Public Health 2016;45(07):875-884

6 Temgoua MN, Tochie JN, Agbor VN, Tianyi FL, Tankeu R, Danwang C. Simple mortality predictive models for improving critical care in resource-limited settings: an insight on the modified early warning score and rapid emergency medical score. Int J Appl Basic Med Res 2018;8(03):199-201

7 Park JE, Chung KS, Song JH, et al. The C-Reactive protein/albumin ratio as a predictor of mortality in critically ill patients. J Clin Med 2018;7(10):333

8 Siddiqui I, Jafri L, Abbas Q, Raheem A, Haque AU. Relationship of serum procalcitonin, $C$-reactive protein, and lactic acid to organ failure and outcome in critically ill pediatric population. Indian J Crit Care Med 2018;22(02):91-95. Doi: 10.4103/ijccm. IJCCM_4_17

9 Abboud R, Charcosset C, Greige-Gerges H. Interaction of triterpenoids with human serum albumin: a review. Chem Phys Lipids 2017;207(Pt B):260-270

10 Leite HP, Rodrigues da Silva AV, de Oliveira Iglesias SB, Koch Nogueira PC. Serum albumin is an independent predictor of clinical outcomes in critically ill children. Pediatr Crit Care Med 2016;17(02):e50-e57

11 Oh J, Kim SH, Park KN, et al. High-sensitivity C-reactive protein/albumin ratio as a predictor of in-hospital mortality in older adults admitted to the emergency department. Clin Exp Emerg Med 2017;4(01):19-24

12 Pollack MM, Patel KM, Ruttimann UE. PRISM III: an updated pediatric risk of mortality score. Crit Care Med 1996;24(05): 743-752

13 Kaur M. C-reactive protein: a prognostic indicator. Int J Appl Basic Med Res 2017;7(02):83-84

14 Deng ZC, Zhao P, Cao C, et al. C-reactive protein as a prognostic marker in chronic obstructive pulmonary disease. Exp Ther Med 2014;7(02):443-446

15 Li G, Jia P, Zhao J, et al. Usefulness of RBC distribution width and C-reactive protein to predict mortality in pediatric noncardiac critical illness. Am J Emerg Med 2019;37(12):21432150

16 Gülcher SS, Bruins NA, Kingma WP, Boerma EC. Elevated Creactive protein levels at ICU discharge as a predictor of ICU outcome: a retrospective cohort study. Ann Intensive Care 2016;6 (01):5

17 Vázquez Martínez JL. Admission hypoalbuminemia: ready for including it in the pediatric prognostic scores? Pediatr Crit Care Med 2016;17(02):180-181

18 Kumar S, Aroor S, Kini PG, Mundkur S, Moideen A. Hypoalbuminemia as a marker of adverse outcome in children admitted to pediatric intensive care unit. Indian J Child Health 2018;5(01): 6-10

19 Lakkappa L, Penta VBT. A study to assess the outcome of critically ill children with hypoalbuminemia admitted in a 
tertiary care center. Indian J Child Health (Bhopal) 2018;5(09): 576-578

20 Moustafa A, Al Halawany A, Rafa M. Evaluation of hypoalbuminemia as a predictor of clinical outcome in critically ill children in Alexandria University Children's Hospital. J Med Sci Clin Res 2018;6(01):32299-32306

21 Knaus WA, Wagner DP, Draper EA, et al. The APACHE III prognostic system. Risk prediction of hospital mortality for critically ill hospitalized adults. Chest 1991;100(06):1619-1636

22 Soeters PB, Wolfe RR, Shenkin A. Hypoalbuminemia: pathogenesis and clinical significance. JPEN J Parenter Enteral Nutr 2019;43 (02):181-193

23 Ranzani OT, Zampieri FG, Forte DN, Azevedo LC, Park M. C-reactive protein/albumin ratio predicts 90-day mortality of septic patients. PLoS One 2013;8(03):e59321

$24 \mathrm{Kim} \mathrm{MH}$, Ahn JY, Song JE, et al. The C-reactive protein/albumin ratio as an independent predictor of mortality in patients with severe sepsis or septic shock treated with early goal-directed therapy. PLoS One 2015;10(07):e0132109
25 Guo S, He X, Chen Q, et al. The C-reactive protein/albumin ratio, a validated prognostic score, predicts outcome of surgical renal cell carcinoma patients. BMC Cancer 2017;17(01):171

26 Arima K, Yamashita Y-I, Hashimoto D, et al. Clinical usefulness of postoperative C-reactive protein/albumin ratio in pancreatic ductal adenocarcinoma. Am J Surg 2018;216(01): $111-115$

27 Çınar T, Çağdaş M, Rencüzoğulları İ, et al. Prognostic efficacy of Creactive protein/albumin ratio in ST elevation myocardial infarction. Scand Cardiovasc J 2019;53(02):83-90

28 Li L, Dai L, Wang X, et al. Predictive value of the C-reactive proteinto-prealbumin ratio in medical ICU patients. Biomarkers Med 2017;11(04):329-337

29 Yllmaz EM, Kandemir A. Significance of red blood cell distribution width and C-reactive protein/albumin levels in predicting prognosis of acute pancreatitis. Ulus Travma Acil Cerrahi Derg 2018;24 (06):528-531

30 Jeong S. Scoring Systems for the Patients of Intensive Care Unit. Acute Crit Care 2018;33(02):102-104 